\title{
Werner Zager
}

Gottesherrschaft und Endgericht in der Verkündigung Jesu 


\title{
Beihefte zur Zeitschrift für die neutestamentliche Wissenschaft und die Kunde der älteren Kirche
}

\author{
Herausgegeben von \\ Erich Gräßer
}

Band 82

Walter de Gruyter · Berlin · New York

1996 


\section{Werner Zager}

\section{Gottesherrschaft und Endgericht in der Verkündigung Jesu}

Eine Untersuchung zur markinischen Jesusüberlieferung einschließlich der Q-Parallelen

Walter de Gruyter · Berlin · New York 1996 
(@) Gedruckt auf säurefreiem Papier,

das die US-ANSI-Norm über Haltbarkeit erfüllt.

\section{Die Deutsche Bibliothek - CIP-Einbeitsaufnabme}

[Zeitschrift für die neutestamentliche Wissenschaft und die Kunde der älteren Kirche / Beihefte]

Beihefte zur Zeitschrift für die neutestamentliche Wissenschaft und die Kunde der älteren Kirche. - Berlin ; New York : de Gruyter.

Früher Schriftenreihe

Reihe Beihefte zu: Zeitschrift für die neutestamentliche Wissenschaft und die Kunde der älteren Kirche

NE: HST

Bd. 82. Zager, Werner: Gottesherrschaft und Endgericht in der Verkündigung Jesu. - 1996

\section{Zager, Werner:}

Gottesherrschaft und Endgericht in der Verkündigung Jesu : eine Untersuchung zur markinischen Jesusüberlieferung einschliesslich der Q-Parallelen / Werner Zager. - Berlin ; New York : de Gruyter, 1996 (Beihefte zur Zeitschrift für die neutestamentliche Wissenschaft und die Kunde der älteren Kirche ; Bd. 82)

Zugl.: Bochum, Univ., Habil.-Schr., 1995

ISBN 3-11-015263-0

\section{ISSN 0171-6441}

(C) Copyright 1996 by Walter de Gruyter \& Co., D-10785 Berlin

Dieses Werk einschließlich aller seiner Teile ist urheberrechtlich geschützt. Jede Verwertung außerhalb der engen Grenzen des Urheberrechtsgesetzes ist ohne Zustimmung des Verlages unzulässig und strafbar. Das gilt insbesondere für Vervielfältigungen, Übersetzungen, Miktoverfilmungen und die Einspeicherung und Verarbeitung in elektronischen Systemen.

\section{Printed in Germany}

Druck: Werner Hildebrand, Berlin

Buchbinderische Verarbeitung: Lüderitz \& Bauer-GmbH, Berlin 
Meiner Frau

Dorothea

und meinen Söhnen

Michael, Raphael und Gabriel

gewidmet 
